\title{
The use of cola for the treatment of gastric impactions in equids
}

\author{
Petra Witt, Signe Hagedoorn, Lieuwke C. Kranenburg and Robin van den Boom \\ Department of Clinical Sciences, Faculty of Veterinary Medicine, Utrecht University
}

\begin{abstract}
Summary: Gastric impactions are an uncommon cause of colic in horses, although they appear to occur more often in Friesians. The administration of cola via nasogastric tube to resolve impactions has been described, but the efficacy of this treatment has not been reported. The aim of the study was to compare the success of treatment of gastric impactions with and without the use of cola and to determine whether Friesians are more often affected by gastric impactions than other breeds. For this retrospective descriptive case series, patient records were retrieved (2003-2019) and 125 horses with gastric impactions identified. The outcome, defined as discharge from the hospital, was compared between horses that were treated with cola and those that were not. The percentage of Friesians in the group of horses with gastric impactions was compared to that in the population admitted to our clinic and treatment success in Friesians was compared to that in other breeds. Overall $72 / 125$ (57.6\%) horses with gastric impactions were discharged from the hospital, but the likelihood of survival was significantly greater for horses treated with cola $(48 / 58=82.8 \%$ vs. $24 / 67=35.8 \%, P<0.001)$. In 66 cases in which the impaction was resolved an estimate was made of the number of days taken for this to occur. The average time until resolution was 2.6 days (range 1-1 1). Of the 125 horses with gastric impactions 39 (31.2\%) were Friesians, a significantly higher percentage than in our hospital population (9.4\%, P<0.001). Also, Friesians treated with cola were less likely to survive $(12 / 18=66.7 \%)$ than other breeds $(36 / 40=90 \%, P=0.03)$. In conclusion, gastric impactions in horses are more likely to be resolved when treatment includes the nasogastric administration of cola. Friesian horses are more likely to develop gastric impactions than other breeds and less likely to survive.
\end{abstract}

Keywords: equine, horse, stomach, gastric impaction, cola, colic

Citation: Witt P., Hagedoorn S., Kranenburg L. C., van den Boom R. (2021) The use of cola for the treatment of gastric impactions in equids. Pferdeheilkunde 37, 588-596; DOI 10.21836/PEM20210604

Correspondence: Petra Witt, Department of Clinical Sciences, Faculty of Veterinary Medicine, Utrecht University, Yalelaan 112,3584 CM, Utrecht, The Netherlands; p.witt@uu.nl

Received: April 12, 2021 | Accepted: June 17, 2021

\section{Introduction}

Gastric impaction is a rare and poorly defined disease in horses and ponies, characterised by persistent and progressive accumulation of dehydrated ingesta in the stomach (Freeman 2011, Bird et al. 2012). A plant-based concretion can also be referred to as a phytobezoar (Naramore et al. 2015, Livesey et al. 2020). These impactions can be either primary or secondary in nature, although the distinction is not always clear and this classification is somewhat controversial, as it is often not possible to rule out all possible primary causes (Bird et al. 2012). Similarly, Tallon et al. (2020) distinguished lone gastric impactions and those associated with other gastrointestinal $(G l)$ disturbances, such as grass sickness, strangulating obstructions, peritonitis and ileus, but indicate that it is very hard to diagnose lone $\mathrm{Gl}$ definitively without additional diagnostics, such as exploratory laparotomy. Rapid eating, overeating, poor dentition, improper mastication, feed that swells or forms a coagulum after consumption, coarse roughage, high fibre diets and inadequate water consumption are considered to play a role in the development of gastric impactions (Boswinkel et al. 2007, Sutton 2014, Sanchez 2018, Livesey et al. 2020). Foreign bodies and indigestible objects can also cause a gastric impaction but almost never occur in horses. A very specific cause of gastric impaction is the consumption of persimmon fruits, as reported in parts of the United States of America (Cummings et al. 1997, Kellam et al. 2000, Rodriguez-Hurtado et al. 2007). Liver or pancreatic disease is thought to play a role in some cases of gastric impaction (Freeman 2011, Parker et al. 2011, Yamout et al. 2012) and issues with gastric motility or secretion may also contribute (Freeman 2011, Vainio et al. 2011). In one case, mild vagal fibre loss was found in an unspecified region of the stomach wall, associated with inflammatory changes (Klier et al. 2017). Schusser et al. (2000) found muscular hypertrophy and reduced neuron density in horses with chronic recurrent caecal impactions, and a similar mechanism could play a role in the formation of gastric impactions. Neurological dysfunction was also listed by Müller et al. (1995) as a possible contributing factor and acquired or congenital obstruction and stenosis or polyps of the pylorus have been reported as mechanical impairments to gastric emptying (McGill and Bolton 1984, Church and Baker 1986, Venner 2004, Bezdekova and Hanak 2009, Furness et al. 2013). Gradual enlargement of the stomach after chronic dilatation might affect motility (Müller et al. 1995, Scheideman and Huthmann 2011, Becker et al. 2017, Klier et al. 2017). However, the origin of an impaction cannot always be determined and an underlying cause often remains uncertain, even if post-mortem examination is performed (Klier et al. 2017). 
There are few data with regard to breed predisposition. Some older reports suggest that ponies are most commonly affected (Jones et al. 1972, Honnas and Schumacher 1985, Owen et al. 1987 Rodriguez-Hurtado et al. 2007), whereas in more recent publications the majority of cases occurred in horses and only 0-10\% in ponies (Vainio et al. 2011, Bird et al., Bäuerlein et al. 2019). However, progressive gastric dilatation and aggregation of feed components along the major curvature have been described specifically in Friesian horses, in which breed a primary neurological dysfunction was suspected (Sutton 2014). Winfield and Dechant (2015) also indicated that Friesians were over-represented, compared to their normal clinic population, in a study on primary stomach ruptures, although Friesians only comprised 3/47 cases, as were draught horses. In the case of Friesians, they suspected that this may have been due to increased pain tolerance, motility dysfunction or underlying tissue defects, factors which are also likely to play a role in the development and diagnosis of gastric impaction.

Gastric impactions may be acute or chronic and the clinical signs associated with the condition are often subtle and/or non-specific, especially to start with (Huskamp et al. 2000, Steinberg et al. 2007, Vainio et al. 2011, Stroth and Belz 2014), and difficult to diagnose (Scheidemann and Huthmann 2011 ). In many cases a diagnosis is only made once the impaction has reached an advanced stage (Klier et al. 2017). The most commonly reported signs associated with gastric impaction are anorexia, weight loss, emaciation, (recurrent) colic signs and sometimes foul-smelling eructation (Bird et al. 2012, Bäverlein et al. 2019, Sanchez 2018). Other, less common, symptoms include lethargy and pyrexia (Vainio et al. 2011, Bäverlein et al. 2019).

The clinical presentation and history may lead to a suspicion of gastric impaction. This suspicion may be supported by finding a full stomach on gastroscopy, following a normally adequate fast of 18-24 hours (Sanchez 2018). There does not appear to be a consensus regarding the required period of fasting, with suggestions ranging from 12-24 hours (Lester 2004, Vainio et al. 2011, Bird et al. 2012, Sanchez 2018). Also, there may be natural variation among horses in the time required for gastric emptying (Freeman 2011), which is also influenced by diet (Boswinkel et al. 2007). Many horses with a gastric impaction demonstrate colic and they may undergo exploratory laparotomy, during which impaction can be detected by palpation of the stomach. Transcutaneous ultrasonographic examination is a non-invasive, simple and rapid method of detecting gastric dilatation (Lores et al. 2007, Scheidemann and Huthmann 2011, Klier et al. 2017). In the case of gastric emptying disorders, hyperechogenic material is present within the stomach, which produces an acoustic shadow in the lumen (Reef 1998). The acoustic window for the stomach is between the $8^{\text {th }}$ and $15^{\text {th }}$ intercostal space, covering not more than five intercostal spaces (Scharner 2011 , Cavalleri et al. 2013). When diagnosing chronic dilatation, gastric dimensions are reported across at least five intercostal spaces (Reef 1998, Stroth and Belz 2014). To confidently identify delayed gastric emptying, repeated ultrasonographic examinations are recommended (Reef 1998, Klier et al. 2017). In ponies and miniature horses, abdominal radiographs may allow detection of the enlarged stomach (San- chez 2018) and in rare cases a diagnosis of gastric impaction can be made by rectal examination, especially if the stomach contains more than 30-35 litres (Hutyra et al. 1945, Müller 1995, Huskamp et al. 2003, Klier et al. 2017, Bäuerlein et al. 2019). Finally, post-mortem examination may reveal gastric impaction and evidence of potential underlying causes can be investigated, although these are not always found (Klier et al. 2017 ).

If horses with gastric impaction show colic, pain management should be instituted and the impaction can sometimes be resolved by gastric lavage via nasogastric tube, using large volumes of fluid (Vainio et al. 2011, Bird et al. 2012). Alternatively, fluid may be injected into the impaction, to soften it, during laparotomy (Bird et al. 2012). Successful treatment by gastrotomy and evacuation of the gastric contents has been reported, although access to the stomach is challenging and carries a high risk of contaminating the abdominal cavity and the subsequent development of peritonitis (Owen et al. 1987, Freeman 2011 ). Prokinetic drugs, including metoclopramide, have also been used in the treatment of (chronic) cases of gastric dilatation (Bäverlein et al. 2019).

Cola was first reported for the treatment of gastric bezoars in humans, administered either through a nasogastric tube (Ladas et al. 2002) or by direct infusion into the bezoar under endoscopic guidance (Sechopoulos et al. 2004). Cola, or other carbonated beverages, are now commonly used in human patients to disintegrate gastric and intestinal phytobezoars and diospyrobezoars (Chung et al. 2006, Lee et al. 2006, Ladas et al. 2013, Iwamuro et al. 2015), with gastric phytobezoar resolution using carbonated beverages being achieved in $91.3 \%$ of cases in human patients, either as a single treatment, or combined with further endoscopic techniques (Ladas et al. 2013). Livesey et al. (2020) reported the successful treatment of an oesophageal obstruction in a horse by a phytobezoar using cola, which has also been used successfully to break up gastric and enteric diospyrobezoars in horses caused by persimmon fruits (Rodriguez-Hurtado et al. 2007, Banse et al. 2011). Bird et al. (2012) also used diet cola in some cases of gastric impaction. The authors are aware of only one study that investigated the use of cola to treat (primary) gastric impactions in horses in a large case series (Tallon et al. 2020).

The prognosis of gastric impaction, especially chronic cases, is considered poor by some, with 16/17 horses being euthanized in one study (Scheidemann and Huthmann 2011) and only 5/12 cases treated successfully as reported in another paper (Bird et al. 2012). Müller et al. (1995), on the other hand, suggested that patients with chronic gastric dilatation could tolerate and live with limited chronic enlargement and Bäuerlein et al. (2019) reported that 17/20 cases of chronic gastric dilation survived long-term when treated with metoclopramide per os, including three cases in which the stomach was never completely empty. Vainio et al. (2011) found a similar survival rate (18/20 horses), while results reported by Tallon et al. (2020) are slightly less favourable, with 68/113 $(60 \%)$ horses with gastric impaction surviving to discharge.

In the present study the findings of 125 equids with a gastric impaction are presented, with particular emphasis on the 
breed, presenting complaint(s), selected clinical and clinicopathological parameters, treatment and outcome. Specific aims of the study were to determine if Friesian horses were over-represented, and if treatment with cola was associated with higher survival.

\section{Materials and methods}

The clinical records of horses presenting to Utrecht University's equine clinic between 2003 and 2019 were reviewed to identify cases of gastric impaction. A diagnosis of gastric impaction was based on gastroscopy, exploratory celiotomy, abdominal ultrasonography, rectal palpation, post-mortem examination, or a combination thereof. Gastroscopy was performed using a flexible, $3.2 \mathrm{~m}$ long video endoscope from Storz Company (Tuttlingen, Germany) and the stomach considered to be impacted if food material precluded visualisation of the margo plicatus (Fig. 1), following a minimum of

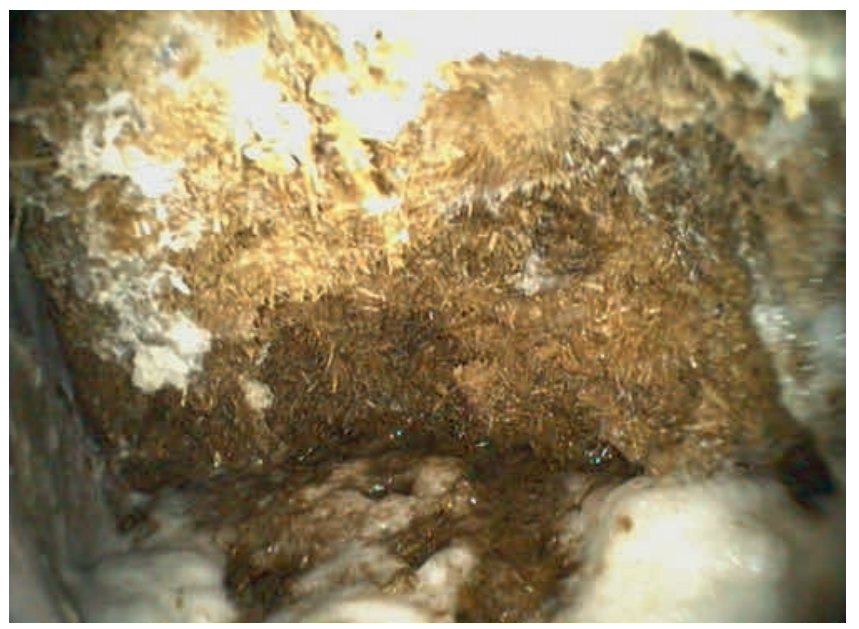

Fig. 1 Gastroscopic image of a gastric impaction, with a mass of feed material precluding visualisation of the majority of the stomach, including the margo plicatus. I Gastroskopisches Bild einer Magenobstipation, mit fehlender Sicht auf den Hauptteil des Magens einschließlich der Margo plicatus aufgrund von Futtermassen.

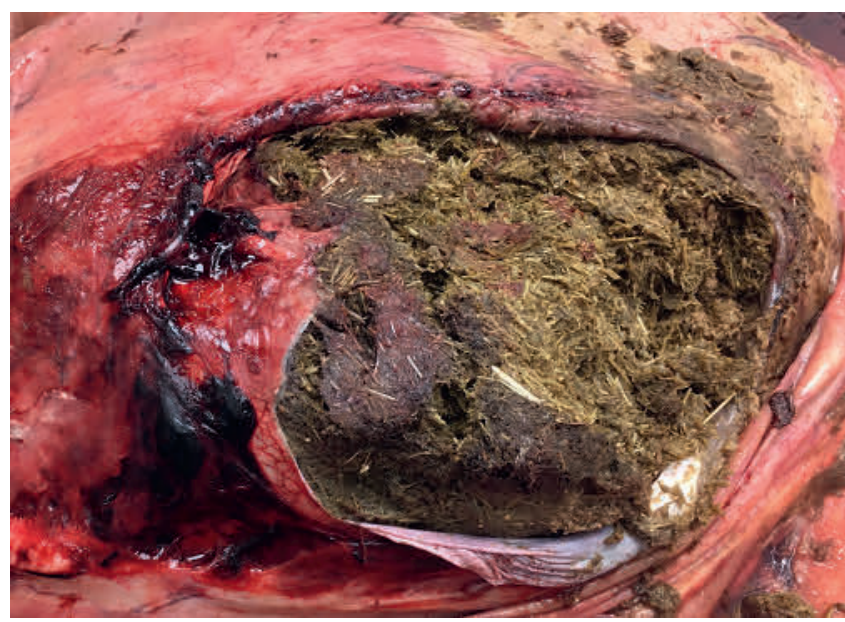

Fig. 2 Post-mortem photograph of a ruptured, impacted stomach, showing the firm feed mass and the rupture, with haemorrhage, of the stomach wall. | Post-mortem Foto eines rupturierten, obstipierten Magens mit fester Futtermasse und Ruptur mit Blutung der Magenwand.
16 hours of starvation (Vainio et al. 2011 1). The diagnosis was made at surgery if an abnormally enlarged stomach, containing a firm impaction and extending to, or beyond, the last rib, was palpated (Bird et al. 2012). Similarly, impaction of the stomach was confirmed by post-mortem examination if a large and firm food mass was present (Fig. 2) and no other abnormalities of the gastrointestinal tract were identified (Klier et al. 2017). The ultrasonographic appearance of a gastric impaction is of a markedly distended stomach, extending over 5 or more intercostal spaces on the left side of the abdomen, often far beyond the $12^{\text {th }}$ intercostal space and even to the lumbar fossa (Reef 1998, Lores et al. 2007). In extreme cases the distended stomach may contact the ventral abdominal wall (Müller et al. 1995) and can be imaged there. On rare occasions an impaction of the stomach was palpated per rectum as a large, firm structure, extending caudally to the level of the left kidney, usually with the spleen displaced medially and/or caudally (Bäuerlein et al. 2019). Cases were included if the gastric impaction was considered to determine the case outcome. Horses with gastric impaction considered to be secondary to intestinal obstruction were excluded, but cases where gastric impactions were considered to have occurred independently of other intestinal diseases were included.

Horses were fasted until the impaction was considered to have been resolved, based on one or more diagnostic criteria as described above, and the number of days between diagnosis and resolution of the impaction were recorded. In other cases, resolution of the impaction was not confirmed, but reintroduction to feed was initiated based on the findings of clinical examination and the general demeanour of the horse.

The signalment (breed, age, sex), history, presenting signs, clinical and clinicopathological findings, treatment and outcome were recorded. Specifically, the use of cola, as part of the treatment regimen was recorded. Given the retrospective nature of the study, the volume and frequency of cola administration could not be accurately determined in all cases, and these data were not included. However, in our clinic most large adult horses that are treated with cola for a gastric impaction receive approximately 1.5 to $2.0 \mathrm{~L}$, roughly $3-4 \mathrm{~mL} /$ $\mathrm{kg}$, at a time. Whether or not and how often this is repeated depends on the estimated severity of the impaction and the results of the follow-up gastroscopy. Survival was defined as discharge from the hospital.

Data were analysed using commercial software (SPSS version 26, IBM). Normality of data was assessed and data found to be normally distributed, either directly (white blood cell count, age) or after log transformation (heart rate, haematocrit, lactate and glucose). Differences in heart rate, haematocrit, white blood cell (WBC) count, blood lactate and glucose concentrations between survivors and non-survivors were tested using a 2-sided t-test. Differences in the percentage of cases with fever and leukopenia between survivors and non-survivors was assessed using a chi-squared test. A P-value $<0.05$ was considered significant.

The percentage of Friesian horses presented to the internal medicine section of the Equine department was recorded for 2019 and compared to the percentage of Friesians with gastric impactions using a chi-squared test. In addition, the mean 
age of Friesian horses was compared to that of Warmblood horses and other horse breeds, also using a 2-sided t-test. The outcome (survival to discharge) was compared between horses that were treated with cola and those that were not, and treatment success in Friesians was compared to that in other breeds, both with and without the use of cola, also using a chi-squared test.

\section{Results}

Between 2003 and 2019, 125 horses, ponies and donkeys were identified with a gastric impaction. Of these 125 cases, $50(40 \%)$ were Warmbloods, 39 (31\%) Friesians, 13 (10\%) ponies, 8 (6\%) Haflinger horses, 3 (2\%) donkeys and 12 (10\%) other horse breeds, including one Irish Cob and one Fiord horse. The percentage of Friesians with a gastric impaction was significantly higher than the percentage of Friesian horses presented to the internal medicine section of our hospital (9.4\%, P<0.001). Warmblood horses comprise the majority of the normal population in our clinic and were not over-represented in this study. The mean age of the Friesian horses with a gastric impaction $(n=40)$ was 9.2 years, and significantly

\begin{tabular}{lc}
\hline $\begin{array}{l}\text { Table } 1 \\
\text { paction. }\end{array}$ & $\begin{array}{c}\text { Frequency of symptoms shown by horses with gastric im- } \\
\text { Symptomhäufigkeit von Pferden mit Magenobstipation. }\end{array}$ \\
\hline Symptom & Number of horses showing symptom \\
\hline Colic & 105 \\
\hline Anorexia & 16 \\
\hline Dullness & 16 \\
Fever & 12 \\
\hline Diarrhoea & 3 \\
Weight loss & 3 \\
Dysphagia & 1 \\
\hline Dyspnea & 1 \\
\hline Distended abdomen & 1 \\
\hline Shock & 1 \\
\hline
\end{tabular}

$(p=0.0003)$ lower than Warmbloods $(n=48$, mean age 12.0 years) and other breeds ( $n=34$, mean age 14.1 years).

The most common presenting complaints were colic, anorexia, dullness and fever (Table 1). Other signs were weight loss, diarrhoea, dyspnoea, dysphagia, a distended abdomen and shock.

The heart rate, haematocrit and blood lactate concentration on admission were significantly higher in non-survivors than in survivors (Table 2). The mean blood glucose concentration of all cases was $7.6 \mathrm{mmol} / \mathrm{L}$ (reference range $3.8-5.6 \mathrm{mmol} / \mathrm{L}$ ), but there was no difference between survivors and non-survivors. There was no difference in WBC count or body temperature between survivors and non-survivors and no difference in the number of horses with leukopenia or fever between groups. In total, 38/125 (30\%) horses had leukopenia (WBC $\left.<6 \times 10^{9} / \mathrm{L}\right), 22 / 72(31 \%)$ survivors and 16/53 (30\%) non-survivors. Sixteen of $103(16 \%)$ cases had fever, 8/66 (12\%) survivors and 8/37 (22\%) non-survivors.

Overall, 72/125 (57.6\%) horses with gastric impactions were discharged from the hospital, but the likelihood of survival was significantly greater for horses treated with cola, compared to those not treated with cola $(48 / 58=82.8 \%$ vs. $24 / 67=35.8 \%, P<0.001)$. Also, Friesian horses treated with cola were less likely to survive $(12 / 18=66.7 \%)$ than other breeds when they received cola $(36 / 40=90 \%, P=0.03)$. In horses that survived the mean time to resolution of the gastric impaction was 2.6 days (range 1-11 days).

Long-term follow-up was not available for the vast majority of cases, but gastric impaction recurred in at least two cases, 7 and 45 days after discharge, and another horse was euthanised 3 days after discharge because of recurring colic, although another gastric impaction was not confirmed.

\section{Discussion}

The percentage of Friesian horses with gastric impactions was higher than in the population of horses presented to the internal medicine division, indicating that they are more likely to develop gastric impactions than other breeds. Friesians,

Table 2 Selected clinical and clinicopathological variables on admission in 125 horses with gastric impaction, for all cases, survivors and nonsurvivors. Values are presented as mean (heart rate, rectal temperature, blood glucose concentration white blood cell count, haematocrit and blood lactate concentration) or number of cases (\%, fever and leukopenia). ${ }^{*}$ indicates a significant difference between survivors and non-survivors. Ausgewählte klinische und klinisch-pathologische Variablen bei Klinikeinweisung von 125 Pferden mit Magenobstipationen, für alle Fälle, überlebende und nichtüberlebende Pferde. Werte sind dargestellt als Mittelwert (Herzfrequenz, Körperinnentemperatur, Blutglukosekonzentration mit weißem Differenzialblutbild, Hämatokrit und Laktatkonzentration im Blut) oder Anzahl der Fälle (\%, Fieber und Leukopenie). *Indiziert einen signifikanten Unterschied zwischen überlebenden und nichtüberlebenden Pferden.

\begin{tabular}{|c|c|c|c|c|}
\hline & All cases & Survivors & Non-survivors & ref range \\
\hline Heart rate (bpm) & 53 & 48 & $59^{*}$ & $24-40$ \\
\hline Rectal temperature $\left({ }^{\circ} \mathrm{C}\right)$ & 38.0 & 37.9 & 38.1 & $37.4-38.0$ \\
\hline Fever $\left(>38.5^{\circ} \mathrm{C}\right)$ & $16 / 103(16 \%)$ & $8 / 66$ (12\%) & $8 / 37$ (22\%) & N/A \\
\hline Blood glucose concentration (mmol/L) & 7.6 & 7.2 & 8.0 & $3.8-5.6$ \\
\hline White blood cell count $\left(\times 10^{9} / \mathrm{L}\right)$ & 7.5 & 7.8 & 7.2 & $6.0-10.0$ \\
\hline Leukopenia (WBC $\left.<6 \times 10^{9} / \mathrm{L}\right)$ & $38 / 125(30 \%)$ & 22/72 (31 \%) & 16/53 (30\%) & N/A \\
\hline Haematocrit (L/L) & 0.37 & 0.34 & $0.41^{*}$ & $0.28-0.42$ \\
\hline Blood lactate concentration (mmol/L) & 3.1 & 2.0 & $4.7^{*}$ & $<1.2$ \\
\hline
\end{tabular}


Haflinger horses, Irish Cobs and Fiord horses are often considered to be cold-blooded, or draught horses and these all appear to be over-represented in this case series of gastric impactions. The 20 cases of gastric impactions reported by Vainio et al. (2011) included a relatively large number (6) of Finnhorses, which are considered to be light draught horses. Friesians and draught horses were also over-represented in a study on primary gastric ruptures (Winfield and Dechant 2015) and some of these may have suffered an impaction prior to rupture of the stomach. Friesians have previously been shown to be prone to mega-oesophagus (Komine et al. 2014, Ploeg et al. 2015) and aortic rupture (Saey et al. 2016), which appear to be associated with the presence of abnormal collagen and possibly elastin (Ploeg et al. 2015, Saey et al. 2016), and they also appear to have a higher rate of collagen degradation than Warmbloods (Saey et al. 2018). It is conceivable that a similar collagen disorder exists in the stomach of Friesian horses and that this contributes to the occurrence of gastric impactions.

Chronic gastric impaction and dilatation was described by Hutyra et al. (1945) and causes a gradual adaptation, enlargement, of the stomach (Scheidemann and Huthmann 2011 , Becker et al. 2017). Impaction can result from excessive feed intake or feed that swells after ingestion, but also from innervation disorders (Müller et al. 1995). If the impaction occurs acutely, the sudden distension is likely to cause pain or discomfort. However, if the increase in size occurs over a longer period of time pain is likely to be less severe or absent, as the stomach can adapt. Also, as the stomach dilates further over time, this in itself is likely to affect motility, as the muscular layer becomes thinner and fibrous tissue may replace muscle (Klier et al. 2017) and nervous innervation may also be compromised (Müller et al. 1995). It is conceivable that such changes may occur more readily in Friesian horses, due to their abnormal collagen and elastin composition and higher rate of collagen degradation (Ploeg et al. 2015, Saey et al. 2016, Saey et al. 2018).

The presenting signs shown by the horses in the present case series were similar to those reported previously, and most commonly horses exhibited colic, often mild and recurrent. As reported by others (Huskamp et al. 2000, Vainio et al. 2011, Bird et al. 2012) signs were often subtle, which complicates and/or delays reaching a diagnosis and signs may have been present for some time in a number of horses at the time of presentation. Friesians and draught horses are considered particularly stoic breeds and may not show colic until pain is severe (Winfield and Dechant 2015). Colic in cases of gastric impaction is likely due to stretching and distension of the stomach, although even extreme gastric filling may be associated with minimal signs in some horses (Huskamp et al. 2000). Anorexia seems a logical consequence of gastric distension. Gastric impaction may be associated with fever, as was the case in approximately $10 \%$ of horses in the current series and $20 \%$ of those reported by Vainio et al. (2011). In addition, 30\% of cases were leukopenic on admission, very similar to the $33 \%$ reported by Vainio et al. (2011) and fever and leukopenia suggest (systemic) inflammation. In some cases of gastric impactions partial ruptures (not all layers involved) were seen at post-mortem examination and fever and leu- kopenia may indicate pending, partial or complete, gastric rupture. Some horses may have had (preperforative) peritonitis. In horses with gastric rupture the rectal temperature varied and was probably dependent on the time relative to rupture (Winfield and Dechant 2015).

Heart rate, haematocrit and blood lactate concentration were higher in non-survivors than in survivors. This probably reflects a more serious condition at the time of presentation. Dehydration and/or hypovolemia were likely a result of not drinking, or consumption of less water than normal, as horses mainly drink around the time of eating (Freeman et al. 2021) and horses with gastric impactions were often anorectic or had a reduced appetite. Many horses presented with hyperglycaemia (mean glucose concentration was $7.6 \mathrm{mmol} / \mathrm{L}$, reference $3.9-5.6 \mathrm{mmol} / \mathrm{L}$ ), which is considered to be a sign of stress in horses, and the blood glucose concentration may be associated with a worse prognosis for survival in horses with gastrointestinal disease (Hassel et al. 2009).

A suspicion of gastric impaction can be difficult to confirm, although gastroscopy is usually considered most useful in establishing a diagnosis (Freeman 2011, Sanchez 2018). However, gastric emptying is influenced by various factors and even normal horses eating a hay diet may have a dehydrated mass that fills the stomach (Husted 2009) and distension is difficult to assess by gastroscopy (Murray 2008). Also, the time of fasting required for the equine stomach to empty has not been definitively determined. Vainio et al. (2011) considered a gastric impaction to be present if the margo plicatus could not be visualised because of a food mass when the horse had been fasted for a minimum of 16 hours. The same definition was used in the current case series, although repeated gastroscopy when horses are fasted longer, as was performed in some horses, may strengthen the diagnosis. Transabdominal ultrasonography can help determine the size of the equine stomach and when the stomach can be imaged in 5 or more intercostal spaces, often far beyond the $12^{\text {th }}$ intercostal space and even to the lumbar fossa, it is considered to be distended (Reef 1998, Lores et al. 2007). In extreme cases the distended stomach may contact the ventral abdominal wall (Müller et al. 1995) and can be imaged there. However, the degree of distension is hard to establish, as the stomach will expand in all directions. Occasionally, if a gastric impaction is extremely large, it may be palpable per rectum, along with caudal displacement of the spleen (Owen et al. 1987, Müller et al. 1995, Parker et al. 2011), although the diagnosis cannot be ruled out by the absence of abnormal findings on rectal palpation.

Enteral fluid therapy is contraindicated in horses with complete gastrointestinal obstruction (Lopes et al. 2003) but gastric impaction usually does not cause a complete obstruction, as mineral oil does pass. A limited number of case reports suggest that mineral oil is not an effective treatment for gastric impaction in horses (Honnas and Schumacher 1985, Owen et al. 1987). Vainio et al. (2011) reported that $90 \%$ of gastric impactions resolved with enteral fluid therapy using 2-10 litres of isotonic fluid, administered every few hours. They speculate that enteral fluid remaining in the stomach may help soften the contents and break down the impaction and recommend the use of enteral fluid therapy for gastric 
impactions. In addition to softening the gastric contents, enteral fluids are thought to activate the gastrocolic reflex and stimulate motility (Lopes et al. 2004).

In the present study, gastric impactions in horses were more likely to be resolved when treatment included the nasogastric administration of cola. Similarly, Tallon et al. (2020) reported that horses with gastric impaction treated with enteral carbonated diet cola were nearly eight times more likely to survive than those that were not. The frequency, amount and duration of treatment with cola was often not clearly recorded, which is one of the main limitations of this retrospective study. For that reason, it was only recorded whether horses were treated with cola or not. In future, prospective, trials the volume and frequency of cola administration must be established. Currently, in our clinic, large adult horses that are treated with cola usually receive approximately 1.5 to $2.0 \mathrm{~L}$, roughly $3-4 \mathrm{~mL} / \mathrm{kg}$, at a time. That is slightly less than, but the same order of magnitude, as reported by Rodriguez-Hurtado et al. (2007), who used $700 \mathrm{~mL}$ in a $123-\mathrm{kg}$ pony $(5.7 \mathrm{~mL} / \mathrm{kg})$ to help resolve a gastric impaction, and that was chosen because the same volume was used in a human of similar weight (Sechopoulos et al. 2004). When Ladas et al. (2002) first used cola to treat phytobezoars in human patients they administered $3 \mathrm{~L}$ over a $12 \mathrm{~h}$ period. If we assume an average human bodyweight of $75 \mathrm{~kg}$, that equates to $40 \mathrm{~mL} / \mathrm{kg}$, which could be achieved in horses by repeated administration or continuous enteral infusion. The rationale for using cola was the observation by car mechanics that nuts and bolts that could not be unscrewed, could be separated after they had been soaked in cola overnight (Ladas et al. 2002). It appears that cola softens phytobezoars, although the mechanism is unknown. It has been hypothesized that the low $\mathrm{pH}$, of 2.6, and/or the release of carbon dioxide bubbles may help disintegrate the impactions (Ladas et al. 2002, Sechopoulos et al. 2004). In the current case series, the cola was sometimes poured from one jug to another several times to remove carbon dioxide, but usually it is administered directly from the bottle and there did not appear to be any noticeable difference in effectiveness or discomfort following administration. Gastric phytobezoars are more common in patients with diabetes mellitus (Ladas et al. 2002) and for that reason diet cola was often used to treat them. Initially, diet cola was also used in our clinic, but since approximately 10 years regular cola is usually used. A potential complication of the use of regular cola is laminitis, due to the higher sugar content of regular cola, however this was not seen in the present case series and has not been reported by others (Klier et al. 2017).

Considering the low $\mathrm{pH}$ of cola, one has to consider the potentially painful effect of cola in case of secondary gastric ulceration, which is commonly seen in horses with gastric impactions. The authors have seen adverse effects, such as bruxism, or even colic, in some horses directly after administering the cola. Another reason for this discomfort could be the increased volume. This however, is considered less likely because often these horses are followed up by repeated gastroscopy and also show these signs when the impaction has decreased in size and the ulcers become visible. On the other hand, the authors have also observed that some horses will voluntarily drink a watery mash containing cola.
Potentially, other substances could also be used to soften or dissolve gastric impactions. The use of acetylcysteine has been reported in man (Silva et al. 2002) and, in analogy to its use in resolving meconium impactions in foals, suggested in horses, but no evidence exists for its use in gastric impactions (Klier et al. 2017). Similarly, treatment with Dioctyl Sodium Sulphosuccinate (DSS) seems to be unrewarding in horses with gastric impaction caused by the ingestion of persimmon fruits (Rodriguez-Hurtado et al. 2007).

Additional treatment with prokinetic drugs could have been considered for the treatment of gastric impactions, and prevention of their recurrence. Bäuerlein et al. (2019) report the successful use of oral metoclopramide in horses with gastric impactions, with 17/20 horses surviving long term. However, care must be taken when using this drug, as the use of metoclopramide in an extremely distended stomach may cause gastric rupture (Klier et al. 2017). Two horses in the present case series were treated with cisapride, which has been shown to enhance gastric emptying in horses (King and Gerring 1988, Valk et al. 1998). However, due to the cardiac side effects reported in humans (Tonini et al. 1999), it has become very difficult to obtain cisapride for veterinary use. The parasympathomimetic drug bethanechol is also sometimes used in the management of gastric impactions, and has been shown to promote solid phase gastric emptying in horses (Ringger et al. 1996).

In the present study 72/125 (58\%) horses with a gastric impaction survived, but the success rate was significantly higher $(48 / 58,83 \%)$ in horses treated with cola, and highest in non-Friesian horses treated with cola (36/40, 90\%). The mean time to resolution was 2.6 days, although this was not confirmed in all cases. The prognosis of gastric impactions in horses is considered (very) poor by some (Scheidemann and Huthmann 2011 , Bird et al. 2012), although others have reported a more favourable outcome, with $85-90 \%$ of horses surviving (Bäuerlein et al. 2019, Vainio et al. 2011). There is always a risk of a self-fulfilling prophecy in (veterinary) medicine, if a condition is thought to carry a poor prognosis and the patient is not expected to survive. The results of the present study confirm the impression gained from case reports that cola may help resolve gastric impactions in horses and indicate that the prognosis, in many cases, may be good. Further studies are needed to determine the optimal volume and frequency of administration of cola and if the use of prokinetics can further increase treatment success.

Not only were Friesian horses more likely to develop gastric impactions than those of other breeds, but these impactions were also less likely to resolve, even when horses were treated with cola. It seems likely that factors associated with the increased risk of developing gastric impactions are also to blame for the poorer prognosis, and these probably include abnormal collagen and/or elastin in Friesian horses (Ploeg et al. 2015, Saey et al. 2016). Another possible explanation could lie in the stoic nature of Friesian horses and the possibility that impaction is more chronic in Friesian horses at the time of diagnosis, and initiation of treatment. Bird et al. (2012) found that $6 / 7$ horses with gastric impactions had increased thickness of the stomach wall, often with evidence of fibrosis and/or myositis. These changes suggest a chronic disease 
process and increased wall thickness may negatively impact gastric motility, with possible consequences for resolution and recurrence. In contrast to these findings, Klier et al. (2017) reported that chronic impaction leads to enlargement of the stomach and thinning of the muscular layer, which will negatively affect motility. Either way, it is possible that the chances of resolution of a gastric impaction may diminish the longer the impaction is present.

In conclusion, gastric impaction is an uncommon cause of colic in horses that is more likely to affect Friesians than other horse breeds. The prognosis for the resolution of gastric impactions is good, especially when cola is administered enterally as part of the treatment, but slightly less favourable in Friesians.

\section{Conflict of interest}

No conflicts of interest have been declared

\section{References}

Banse H. E., Gilliam L. L., House A. M. (2011) Gastric and enteric phytobezoars caused by ingestion of persimmon in equids. J. Am. Vet. Med. Assoc. 239, 1110-1116; DOI 10.2460/javma.239.8. 1110

Bäuerlein V., Vervuert I., Venner M. (2019) Chronic gastric dilatation in horses: diagnosis, treatment and feeding management - $\mathrm{A}$ survey of 20 clinical cases. Pferdeheilkunde 35, 129-137; DOI 10.21836/PEM20190205

Becker M., Scheidemann W., Stadtbäumer G. (2017) Magenüberladung und Magendilatation. In: Brehm W., Gehlen H., Ohnesorge B., Wehrend A. (eds), (begründet von Dietz O. und Huskamp B.) Handbuch Pferdepraxis, 4th edition, Enke Verlag, Stuttgart, Germany, 498-502.

Bezdekova B., Hanak J. (2009) Pyloric stenoses in horses: a seven case reports. Veterin. Medicina 54, 244-248; DOI 10.17221/1/2009-VETMED.

Bird A. R., Knowles E. J., Sherlock C. E., Pearson G. R., Mair T. S. (2012) The clinical and pathological features of gastric impaction in twelve horses. Equine Vet. J. 44 (Supplement 43), 105-110; DOI 10.1111/i.2042-3306.2012.00674.x

Boswinkel M., Ellis A. D., Sloet van Oldruitenborgh-Oosterbaan M. M. (2007) The influence of low versus high fibre haylage diets in combination with training or pasture rest on equine gastric ulceration syndrome (EGUS). Pferdeheilkunde 23, 123-130; DOI 10.21836/PEM20070203

Cavalleri J. M., Bienert-Zeit A., Feige K. (2013) Examination of horses with acute colic - clinical pathology and diagnostic imaging. Tierärztl. Prax. G 41, 124-134

Chung Y., Han D., Park Y., Son B. K., Paik C., Jeon Y., Sohn, Joohyun (2006) Huge gastric diospyrobezoars successfully treated by oral intake and endoscopic injection of Coca-Cola. Dig Liver Dis 38, 515-517; DOI 10.1016/i.dld.2005.10.024

Church S., Baker J. R. (1986) Gastric retention associated with acquired pyloric stenosis in a gelding. Equine Vet. J. 18, 332-334; DOI 10.1111/j.2042-3306.1986.tb03644.x

Cummings C. A., Copedge K. J., Confer A. W. (1997) Equine gastric impaction, ulceration, and perforation due to persimmon (Diospyros virginiana) ingestion. J. Vet. Diagn. Invest. 9, 311-313; DOI $10.1177 / 104063879700900315$

Freeman D. E. (2011) Gastric impaction. Equine Vet. Educ. 23, $174-$ 176; DOI 10.1111/i.2042-3292.2010.00206.x
Freeman D. E., Mooney A., Giguère S., Claire J., Evetts C., Diskant P. (2021) Effect of feed deprivation on daily water consumption in healthy horses. Equine Vet. J. 53, 117-124, DOI 10.1111/ evj. 13259.

Furness M. C., Snyman H. N., Abrahams M., Moore A., Vince A., Anderson M. E. (2013) Severe gastric impaction secondary to a gastric polyp in a horse. Can. Vet. J. 54, 979-982; PMCID PMC3781432

Hassel D. M., Hill A. E., Rorabeck R. A. (2009) Association between hyperglycemia and survival in 228 horses with acute gastrointestinal disease. J. Vet. Int. Med. 23, 1261-1265; DOI 10.1111/j.1939-1676.2009.0395.x

Honnas C. M., Schumacher J. (1985) Primary gastric impaction in a pony. J. Am. Vet. Med. Assoc. 187, 501-502; PMID 4055477

Huskamp B., Scheidemann W., Schusser G. F. (2000). Einige seltene Magen- und Duodenum-erkrankungen beim erwachsenen Pferd: Zweiphasige Magenruptur, chronische Magendilatation, Duodenumdilatation mit Hypo- oder Aganglionose, Längsachsendrehung des Duodenum. Prakt. Tierarzt 82, 729-736

Huskamp B., Knopf N., Scharner D. (2003) Spezielle Untersuchungen Magen. In: Die rektale und die sonographische Untersuchung beim Kolikpferd, 2. korrigierte und erweiterte Auflage, was Verlag, München, 38

Husted L. (2009) Pathophysiologic Aspects of the Equine Gastric UIcer Syndrome (EGUS) in Adult Horses - Emphasis on Acid Exposure Patterns and Bacterial Environment. PhD Thesis, Department of Large Animal Clinical Sciences, Faculty of Life Sciences, University of Copenhagen, $50-52$

Hutyra F., Marek F., Manninger R. (1945) Chronische Magenerweiterung. In: Spezielle Pathologie und Therapie der Haustiere, 9. Aufl., Bd. 2, Gustav Fischer Verlag, Jena Kap. 1: Krankheiten des Magens und des Darms, 95-96

Iwamuro M., Okada H., Matsueda K., Inaba T., Kusumoto C., Imagawa A., Yamamoto K. (2015) Review of the diagnosis and management of gastrointestinal bezoars. World J. Gastrointest. Endosc. 16; 7, 336-345; DOI 10.4253/wige.v7.i4.336

Jones D. G., Greatorex J. C., Stockman M. J., Harris C. P. (1972) Gastric impaction in a pony: Relief via laparotomy. Equine Vet. J. 4, 98-99; DOI 10.1111/j.2042-3306.1972.tb03887.x

Kellam L. L., Johnson P. J., Kramer J., Keegan K. G. (2000) Gastric impaction and obstruction of the small intestine associated with persimmon phytobezoar in a horse. J. Am. Vet. Med. Assoc. 216, 1279-1281; DOI 10.2460/javma.2000.216.1279

King J. N., Gerring E. L. (1988) Actions of the novel gastrointestinal prokinetic agent cisapride on equine bowel motility. J. Vet. Pharmacol. Therap. 11, 314-321; DOI 10.1111/j.1365-2885.1988. tb00190.x

Klier J., Blutke A., Emrich D., Beckmann J., Wittschorek J., MedinaTorres C. E. (2017) Chronic gastric importation and dilatation in horses: clinical signs, diagnosis, treatment options and pathologic findings - A case series. Pferdeheilkunde 33, 438-446; DOI 10.21836/PEM20170503

Komine M., Langohr I. M., Kiupel M. (2014) Megaesophagus in Friesian Horses Associated With Muscular Hypertrophy of the Caudal Esophagus. Vet. Pathol. 51, 979-985; DOI 10.1177/0300985813511126

Ladas S. D. Triantafyllou K., Tzathas C., Tassios P., Rokkas T., Raptis S. A. (2002) Gastric phytobezoars may be treated by nasogastric Coca-Cola lavage. Eur. J. Gastroenterol. Hepatol. 14, 801-803; DOI 10.1097/00042737-200207000-00017

Ladas S. D., Kamberoglou D., Karamanolis G., Vlachogiannakos J., Zouboulis-Vafiadis I. (2013) Systematic review: Coca-Cola can effectively dissolve gastric phytobezoars as a first-line treatment. Aliment. Pharmacol. Ther. 37, 169-173; DOI 10.1111/apt.12141.

Lee H., Kang H., Park S., Yi C., Na G., Lee T., Kim S., Song C. (2006) Two cases of phytobezoars treated by administration of Coca-Cola by oral route. Korean J. Gastroenterol. 48, 431-433; PMID 17189928 
Lester G. D. (2004) Gastrointestinal diseases of performance horses. In: Hinchcliff K. W., Kaneps A. J., Geor R. J. (Eds.), Equine sports medicine and surgery. Saunders, Elsevier Ltd., Philadelphia, 1037-1043

Livesey L. C., Yorke E., Parra A., Gray Q., Davies C., Weldon D., Schumacher J., Kimura S., Howard C., Sierra-Rodriguez T. and Mora-Pereira M. (2020) Use of a carbonated beverage to disintegrate a phytobezoar obstructing the intrathoracic portion of the oesophagus of a horse. Equine Vet. Educ. 32, e179-e183; DOI 10.1111/eve.13082

Lopes M. A. F., Hepburn R. J., McKenzie H. C., Sykes B. W. (2003) Enteral fluid therapy for horses. Comp. cont. Educ. Pract. Vet. 25, 390-397; DOI 10.1002/9781118928189.ch21

Lopes M. A. F., White N. A., Donaldson L., Crisman M. V., Ward D. L. (2004) Effects of enteral and intravenous fluid therapy, magnesium sulphate, and sodium sulphate on colonic contents and feces in horses. Am. J. Vet. Res. 65, 695-704; DOI 10.2460/ ajvr.2004.65.695

Lores M., Stryhn H., McDuffee L., Rose P., Muirhead T. (2007) Transcutaneous ultrasonographic evaluation of gastric distension with fluid in horses. Am. J. Vet. Res. 68, 153-157; DOI 10.2460/ ajvr.68.2.153

McGill C. A., Bolton J. R. (1984) Gastric retention associated with a pyloric mass in two horses. Aust. Vet. J. 61, 190-191; DOI 10.1111/j.1751-0813.1984.tb07239.x

Müller E., Donandt D., Pingen C., Zeitelhack M. (1995) Beitrag zur chronischen primären Magendilatation beim Pferd - Ein Fallbericht. Pferdeheilkunde 11, 101-104; DOI 10.21836/PEM19950203

Murray M. J. (2008) Diseases of the stomach. In: The Equine Acute Abdomen, 2nd edn., Eds: Blikslager A., White N. A., Moore J. N., Mair T. S., Teton NewMedia, Jackson, 578-591; DOI 10.1002/9781119063254.ch50

Naramore S., Virojanapa A., Bell M., Jhaveri P. N. (2015) Bezoar in a Pediatric Oncology Patient Treated with Coca-Cola. Case Rep. Gastroenterol. 9, 227-232; DOI 10.1159/000431217

Owen R. A., Jagger D. W., Jagger F. (1987) Two cases of equine primary gastric impaction. Vet. Rec. 121, 102-105; DOI 10.1136/ vr.121.5.102

Parker R. A., Barr E. D., Dixon P. M. (2011) Treatment of equine gastric impaction by gastrotomy. Equine Vet. Educ. 23, 169-173; DOI 10.1111/i.2042-3292.2010.00165.x

Ploeg M., Gröne A., Saey V., de Bruijn C. M., Back W., van Weeren P. R., Scheideman W., Picavet T., Ducro B. J., Wijnberg I., Delesalle C. (2015) Esophageal Dysfunction in Friesian Horses: Morphological Features. Vet. Pathol. 52, 1142-1147; DOI $10.1177 / 0300985814556780$

Reef V. B. (1998) Adult abdominal ultrasonography. In: Equine Diagnostic Ultrasound. W. B. Saunders Co. Philadelphia. 277, 283, 331

Ringger N. C., Lester G. D., Neuwirth L., Merritt A. M., Vetro T., Harrison J. (1996) Effect of bethanechol or erythromycin on gastric emptying in horses. Am. J. Vet. Res. 57, 1771-1775

Rodriguez-Hurtado I., Stewart A., Pellegrini-Masini A. (2007) Successful treatment for a gastric persimmon bezoar in a pony using nasogastric lavage with a carbonated cola soft drink. Equine Vet. Educ. 19,571-574; DOI 10.2746/095777307X215052

Sanchez L. C. (2018) Disorders of the Gastrointestinal System. In: Equine Internal Medicine, Fourth edition, Eds: Reed S. M., Bayly W. M., Sellon D. C., Elsevier, St. Louis, 801-808
Saey V., Ploeg M., Delesalle C., van Loon G., Gröne A., Ducatelle R., Duchateau L., Chiers K. (2016) Morphometric Properties of the Thoracic Aorta of Warmblood and Friesian Horses with and without Aortic Rupture. J. Comp. Pathol. 154, 225-230; DOI 10.1016/i.jcpa.2016.02.001

Saey V., Tang J., Ducatelle R., Croubels S., De Baere S., Schauvliege S., van Loon G., Chiers K. (2018) Elevated urinary excretion of free pyridinoline in Friesian horses suggests a breed-specific increase in collagen degradation. BMC Vet. Res. 14, 139; DOI 10.1186/s12917-018-1454-8

Scharner D. (2011) Abdomen. In: Glatzel P. B. S. (ed.). Atlas der Ultraschalluntersuchung beim Pferd. Schlütersche, Hannover, Germany, 92-113

Scheidemann W., Huthmann S. (2011) A contribution to disease of the equine stomach: chronic gastric impaction and dilatation. In: 4th European College of Equine Internal Medicine Congress Hannover 2011 , proceedings, 45-46

Schusser G., Scheidemann W., Huskamp B. (2000) Muscle thickness and neuron density in the caecum of horses with chronic recurrent caecal impaction. Equine Vet. J. Suppl. 32, 69-73; DOI 10.1111/i.2042-3306.2000.tb05337.x

Sechopoulos P., Robotis J. F., Rokkas T. (2004) Gastric bezoar treated endoscopically with a carbonated beverage: case report. Gastrointest. Endosc. 60, 662-664; DOI 10.1016/s00165107(04)01872-3

Silva F. G., Goncalves C., Vasconcelos H., Cotrim I. (2002) Endoscopic and Enzymatic Treatment of Gastric Bezoar with Acetylcysteine. Endoscopy 34, 845; DOI 10.1055/s-2002-34265

Steinberg T., Hamann J., Deppenmeier S. (2007) Sekundäre chronische Magenobstipation durch idiopathische muskuläre lleumhypertrophie bei einem Pferd. Pferdeheilkunde 23, 587-592; DOI 10.21836/PEM20070603

Stroth C., Belz J. P. (2014) Diagnostik der chronischen Magendilatation des Pferdes mittels transkutaner Abdominalsonographie und Gastroskopie. Prakt. Tierarzt 95, 2-4

Sutton D. (2014) Disorders of the equine stomach: what do we know and what do we still need to learn? Proceedings European Veterinary Conference Voorjaarsdagen.

Tallon R. E., Hayes C., Dunkel B. M. (2020) Comparison of outcomes for lone and concurrent gastric impactions in 113 hospitalised horses. BEVA congress proceedings, 5. DOI 10.1111/evj.01_13365

Tonini M., De Ponti F., Di Nucci A., Crema F. (1999) Review article: cardiac adverse effects of gastrointestinal prokinetics. Aliment. Pharmacol. Ther. 13,1585-1591; DOI 10.1046/i.13652036. 1999.00655.x

Vainio K., Sykes B. W., Blikslager A. T. (2011) Primary gastric impaction in horses: A retrospective study of 20 cases (2005-2008). Equine Vet. Educ. 23, 186-190; DOI 10.1111/i.2042-3292.2010.00153.x

Valk N., Doherty T. J., Blackford J. T., Abraha T. W., Frazier D. L. (1998) Effect of cisapride on gastric emptying in horses following endotoxin treatment. Equine Vet. J. 30, 344-348; DOI 10.1111/ j.2042-3306.1998.tb04108.x

Venner M. (2004) Pyloric stenosis: a rare disease with a typical anamnesis. Equine Vet. Educ. 16, 176-177; DOl 10.1 111 1/i.20423292.2004.tb00291.x

Winfield L. S., Dechant J. E. (2015) Primary gastric rupture in 47 horses (1995-201 1). Can. Vet. J. 56, 953-958; PMID 26345205

Yamout S. Z., Nieto J. E., Anderson J., de Cock H. E. V., Vapniarsky N., Aleman M. (2012) Pathological evidence of pancreatitis in 43 horses (1986-2011). Equine Vet. J. 44, 45-50; DOI 10.1 $111 /$ i.2042-3306.2012.00636.x 